\title{
LEARNING CHOICES: GENERATING AND INTEGRATING INFORMAL KNOWLEDGE
}

\author{
Márcia PEREIRA and Effie LAW
}

\section{Introduction}

New forms of information technologies (IT) are growingly made available worldwide and also increasingly being used in education and training. Specifically, IT offer unprecedented opportunities and advantages for their users: access to a vast source of information, communicating ideas effectively and efficiently with different people independent of geographical and temporal barriers, externalising thoughts in various modes of representations, to name just a few. We live in a prevalent knowledge society, ${ }^{1}$ and rapid changes in our lives make the need for lifelong and just-in-time learning ${ }^{2}$ evident. Not only in educational institutions, but also at the workplace, learning is ever more a necessity to keep up with the new technological changes and socio-economic demands. Within this context, it becomes ever clearer the need to form creative and sensitive professionals, who are able to effectively respond to the context of a problematic situation. Indeed, inventive thinking, digital literacy, effective communication, and high productivity are the four $21^{\text {st }}$ Century skills ${ }^{3}$ deemed essential for the personal and professional development of people from almost every walk of life.

This paper discusses the need to go beyond the traditional delivery method in education and to adopt a socio-constructivist approach on the design of a learning environment, which can help to deal with this emergent need and challenge. We propose a Learning Management System (LMS) - HyperChoice - that offers the learner a series of learning choices. This variety of choices aim at stimulating the generation and capture of the knowledge produced by learners - Informal Knowledge. The HyperChoice model is presented and its applications are discussed.

\section{Need to go beyond traditional models of teaching}

Despite the large availability of educational technologies, educators and trainers have difficulties to go beyond the traditional 'delivery' model of teaching. ${ }^{4}$ Most 
applications of these technologies impart knowledge to students, without fully exploring the Informal Knowledge that can be generated by the students during the learning process. Several so-called e-learning courses do not go beyond the publication of learning content made available in different formats.

However, the emergent needs of the contemporary society demand people not only with wider skills in different disciplines, but also with adequate awareness and sensitivity to make the most of these skills according to the situation they are in at a specific moment. One should be able to make the best use of her/his own experiences as well as of the experiences of others and apply them to solve specific problems in specific contexts, with creativity and coherence. In order to acquire this ability one has to learn in a different way, not only through ready-made content, but, more importantly, in a learning environment which supports choices in addition to individual and collaborative challenging experiences.

To foster this type of learning, it is necessary to better consider the contribution of the learner during the whole educational process. More people are becoming aware of this need. Companies, for example, are increasingly investing considerable sums in continuous professional development. They recognize that there is a type of knowledge within their institutions, which is widespread and unstructured ${ }^{5}-$ "Informal Knowledge." This type of knowledge is a valuable resource within an organisation. Both higher education and continuous professional development (CPD) can improve learning quality by exploring and integrating Informal Knowledge.

The impact of Informal Knowledge has also been acknowledged by designers of information and communication technologies (ICT). ${ }^{6}$ Despite their observation, the coding of tacit knowledge is still hardly explored in system design. ${ }^{7}$ Hence, there is a need for new design concepts and solutions. Two such solutions are offered by Knowledge Management Systems (KMSs) and Learning Management Systems (LMSs). Both KMS and LMS are expected to improve the construction, collection, and sharing of Formal and Informal Knowledge. Particularly, LMSs are expected to do that with the explicit function of facilitating the learning process. They are supposed to be able to minimise insecurity problems generated by constant technological changes. Besides, LMSs have the potential to provide secure spaces where users can develop a sense of community, share ideas and resources, and learn from each other, via the interaction with content, tools, and other users.

Furthermore, the educational theories also demonstrate a clear move from the positivist view of knowledge as deliverable to the constructivist view of knowledge as constructed by learners, moving from the behaviourist to the constructivist paradigm. 


\section{Giving learners 'choice' and 'voice': HyperChoice}

Having all these issues in mind, we propose the design of a Learning Management System (LMS)-HyperChoice-which meet the needs presented above: giving learners the choice of several learning possibilities via interactions with the learning content and with tutors and other learners, via several tools. HyperChoice will encourage the generation and capture of "Informal Knowledge," making it possible to store it in a repository and a Learning Content Management System (LCMS), facilitating its re-use.

\section{HyperChoice Pedagogical Model}

HyperChoice is based on the socio-constructivist approach, which is coherent with the use of networked learning environments, ${ }^{8}$ favouring learner-oriented processes and collaborative learning. ${ }^{9}$ Within this approach, it is important to provide learners with a choice of learning activities, enabling them to interact with the content in a manner suited to their individual style and needs. Moreover, it is important to provide learning activities that can be developed by the learner alone and in collaboration. That is, to support individual and social cognition. ${ }^{10}$

\section{User Interaction in HyperChoice}

It is important to have high quality and reliable learning content, but that is not enough. The way the learner will make use of this learning content is paramount to determine the quality of the learning process. The learner's interaction with the learning content and the learning environment has significant importance. Thus, the learning content needs to be accessed via a coherent navigational approach, and within a coherent user interaction model. The learner's interaction with the content via the use of appropriate tools in the context of different learning activities will generate Informal Knowledge (Figure 1).

\section{Learning choices and tools}

Taking into account the chosen pedagogical approach - socio-constructivist - and the need for a coherent user interaction model, we suggest a set of four distinct learning modes (see Table 1 for more details). These learning modes are called 'learning hub,' 'learning by doing,' 'learning by playing,' and 'learning by reflection':

- Learning hub: In this mode learners choose between individual and shared views. Modal tools are offered to handle learning units (LUs) or whole courses. Operating on LUs or courses, modal tools allow users to browse, trace path, annotate, flag, and rate. The Informal Knowledge obtained as a result of using the modal tools takes the form of course path, annotations, 


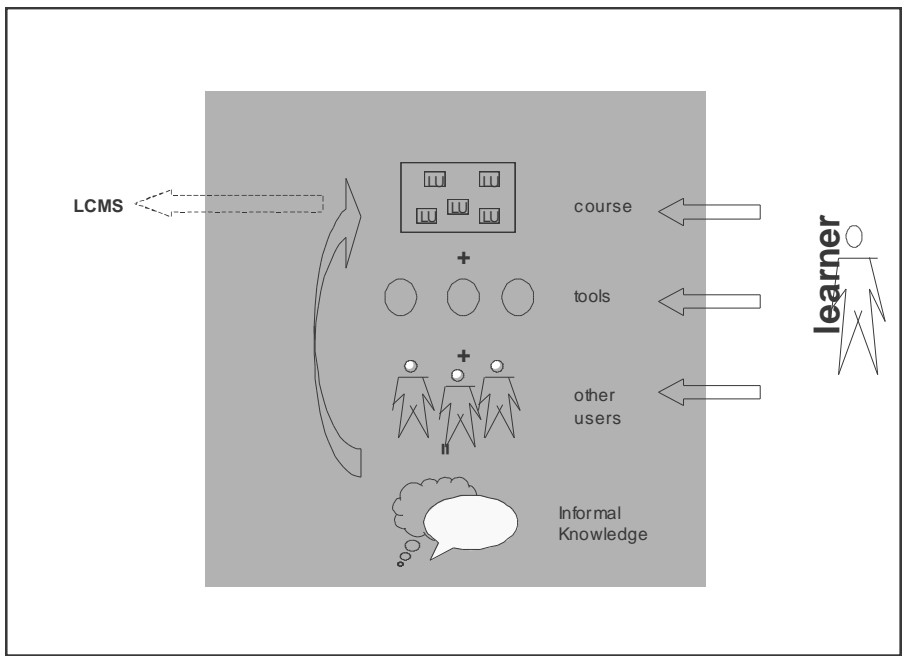

Figure 1: Learner's interactions.

ratings, and marks. The following items are necessary for the implementation of this mode: a LMS database; students' private folders; a mechanism for the generation of didactical metadata; and a course editor in the learning design module of the LMS. In the learning design module, which is closely linked to this mode, teachers will prepare typical learning sequences, define learning targets, motivational issues, embedded questions and answers, and links to problems to be solved in the 'learning by doing' mode and to games in the 'learning by playing' mode.

- Learning by doing: In this mode learners choose between individual and cooperative views. Modal tools are chat, web conferencing, simulation, and a whiteboard. In the whiteboard, learners have modal tools such as open/close, draw, sketch, and annotate.

- Learning by playing: In this mode learners choose between individual and multi-user competition and/or collaborative games. Modal tools will vary according to the specific game, but examples of typical tools are throwing dice, drawing question, checking answer, undoing, and replaying. This mode allows its users to develop reasoning processes and to reinforce learning through individual or competitive play. The user's steps and decisions are recorded and can thus be undone or replayed.

- Learning by reflection: In this mode learners choose between individual and shared views, having the opportunity to develop individual and social 
cognition. In this mode, metacognitive skills - considered to be fundamental in any learning process ${ }^{11}$ — can be developed. Modal tools help learners to reflect upon and plan the learning process. The modal tools are notepad, learning portfolio, concept mapping, image-based forum, and text-based forum. Individual ideas can be shared by adding them to the forums or generating public links to learning units.

Common to all of these four modes are some general functions: login/logout, search, my info, my notes, site map, help, and save. My info gives the user access to her/his private folder. My notes enable annotation, which can be saved in the learner's private folder, be accessed in the 'learning by reflection' mode, or be linked to learning units (LUs) in the learning path.

In the learning hub, learning units can be presented in a sequential way, from introductory sections to concluding ones as assembled by a teacher or an author. Learners can choose their own paths through the learning content and navigate through different layers of the content structure. There will be various forms of navigation, which can be grouped into two main types: one, which is text-based (e.g. expandable list of contents, alphabetical order, keyword-based search) and another, which is image-based (e.g. metaphorical representation of the knowledge domain).

Navigation possibilities shall consider learners' preferences. For example, those learners, who prefer having a general view of the information before choosing to go deeper into a specific part of the content, can choose to see all the overviews or summaries of a course. Alternatively, those learners who are more visually oriented should have the option of browsing all the images of a learning theme, looking at pictures, diagrams, simulations, and video clips. These assets will be used as search filters.

\section{Discussion on HyperChoice use and applications}

In order to fully develop HyperChoice and implement its integration with a LCMS and applying its full potential, several issues need to be further investigated. When using HyperChoice, reacting to and interacting with learning content, learners will produce their own interpretation of it. Using the modal tools, they will produce Informal Knowledge. In the context of such an interaction, a set of research questions call for detailed investigation:

- How will this Informal Knowledge be integrated?

- Will there be a database within the LMS to store these contributions?

- Should the content be revised and then be transformed into Formal Knowledge? 
Table 1: HyperChoice learning modes

\begin{tabular}{|c|c|c|c|c|c|}
\hline Mode & Content & Usage & Tool & Informal Knowledge ${ }^{12}$ & Implementation \\
\hline Learning hub & Course & $\begin{array}{l}\text { Individual and } \\
\text { shared view }\end{array}$ & $\begin{array}{l}\text { Browse } \\
\text { Trace path } \\
\text { Annotate } \\
\text { Flag } \\
\text { Rate }\end{array}$ & $\begin{array}{l}\text { Course path } \\
\text { Annotations } \\
\text { Ratings } \\
\text { Marks }\end{array}$ & $\begin{array}{l}\text { LMS database } \\
\text { Students' private folders } \\
\text { Didactical metadata } \\
\text { Course editor of the } \\
\text { Learning design module }\end{array}$ \\
\hline $\begin{array}{l}\text { Learning by } \\
\text { doing }\end{array}$ & $\begin{array}{l}\text { Tasks with } \\
\text { useful links }\end{array}$ & $\begin{array}{l}\text { Individual and } \\
\text { cooperative work }\end{array}$ & $\begin{array}{l}\text { Chat } \\
\text { Web conference } \\
\text { Simulate } \\
\text { Whiteboard } \\
\text { open / close } \\
\text { draw } \\
\text { sketch } \\
\text { annotate }\end{array}$ & $\begin{array}{l}\text { Solutions } \\
\text { Products } \\
\text { Sketches } \\
\text { Drawings } \\
\text { Annotations }\end{array}$ & $\begin{array}{l}\text { LMS database } \\
\text { Students' private folders } \\
\text { Didactical metadata } \\
\text { Task editor of the } \\
\text { Learning design module }\end{array}$ \\
\hline $\begin{array}{l}\text { Learning by } \\
\text { playing }\end{array}$ & $\begin{array}{l}\text { Games with } \\
\text { useful links }\end{array}$ & $\begin{array}{l}\text { Individual and } \\
\text { multi-user } \\
\text { competition }\end{array}$ & $\begin{array}{l}\text { Throw dice } \\
\text { Draw questions } \\
\text { Check answers } \\
\text { Undo } \\
\text { Replay }\end{array}$ & Game logs & $\begin{array}{l}\text { LMS database } \\
\text { Students' private folders } \\
\text { Didactical metadata } \\
\text { Game editor of the Learning design } \\
\text { module }\end{array}$ \\
\hline $\begin{array}{l}\text { Learning by } \\
\text { reflection }\end{array}$ & Triggers & $\begin{array}{l}\text { Individual and } \\
\text { social cognition }\end{array}$ & $\begin{array}{l}\text { Notepad } \\
\text { Learning portfolio } \\
\text { Concept mapping } \\
\text { Image-based forum } \\
\text { Text-based forum }\end{array}$ & $\begin{array}{l}\text { Notes } \\
\text { Individual portfolio logs } \\
\text { Collaborative portfolio logs } \\
\text { Individual concept maps } \\
\text { Collaborative concept maps } \\
\text { Forum discussion }\end{array}$ & $\begin{array}{l}\text { LMS database } \\
\text { Students' private folders } \\
\text { Didactical metadata } \\
\text { Portfolio editor of the Learning design } \\
\text { module }\end{array}$ \\
\hline
\end{tabular}


HyperChoice could be applied within different disciplinary contexts and ideally all the available modes and tools could be used in the deployment of a course. However, in order to allow the progressive adaptation of existing course material and the gradual acquaintance with the system, course designers should be allowed to choose which modes they want to make use of during a specific course. Learning objects stored in the LCMS can be combined into learning units (LUs), using an assembly tool within the LCMS itself. However, within the LMS there will be a learning design module, where learning designers or teachers should be able to personalise their courses and reorganise the content to be accessed by the different modes:

- Courses, composed by LUs;

- Tasks with useful links to the appropriate Lus;

- Games with useful links to the appropriate Lus; and

- Reflection triggers.

Learning objects consisting of questions and answers, for example, can be combined into a 'game template,' to generate a game to be played in the 'learning by playing' mode, while other learning objects such as case studies can be transformed into tasks to be solved in the 'learning by doing' mode.

Finally, HyperChoice represents a possibility to change the e-learning scenario, giving the user/learner more options to learn according to her/his own learning style and motivation, facilitating the learning process and making it more enjoyable. It also encourages the generation of Informal Knowledge and facilitates its capture and storage for future re-use. Obviously, such a development demands the investigation of a series of issues, such as the degree of re-use of Informal Knowledge, its selection process and classification, its possible integration within a LCMS. These and other issues are interesting questions, which need to be further explored.

\section{Conclusion}

This paper discussed the need to go beyond the traditional 'delivery model' of education and emphasised the need to offer a variety of learning choices to learners, giving them the opportunity to be more active and efficient during the learning process. The model of HyperChoice, a Learning Management System that aims at encouraging the production of informal knowledge and at facilitating its capture and re-use, was presented. Details about the HyperChoice structure, technology and tools were discussed.

HyperChoice contains four different distinct learning modes: 'learning hub,' 'learning by doing,' 'learning by playing,' and 'learning by reflection.' These modes allow learners to explore different learning alternatives and also to develop different skills. 
The interactions with learning content, tutors and other fellow learners can take several forms. The results of these interactions, in the form of Informal Knowledge, can be captured and re-used. Issues necessitating closer investigations in the future research and development activities were also discussed.

Presumably, the HyperChoice LMS model could effectively improve the education and training processes by generating a learning environment that is more conducive to the formation of communities of learners, be they competitive players or reflective thinkers. These learners are sensitive to and aware of the specificities of the context in which they are embedded and also conscious of the needs and ideas of their fellow learners, being able to take creative and efficient decisions when necessary. Nonetheless, the purported benefits of the HyperChoice LMS model entail empirical verifications, which are hopefully to be implemented in the near future.

ACKNOWLEDGEMENTS. The ideas presented in this paper have been extensively discussed with colleagues at the Swiss Federal Institute of Technology and have considerably benefited from their criticism and input. We are thankful to Timo Staub (Centre for Policy Studies, ISN), Christian Schorno and Wilfried Elspass (Centre of Product Design), Sissel Guttormsen and Samuel Schluep (Institute of Hygiene and Applied Physiology).

\section{Notes:}

1 Ron Dearing and the National Committee for Inquiry into Higher Education, Higher Education in the Learning Society (Secretaries of State for Education and Employment, Wales, Scotland, and Northern Ireland, 1997), <http://www.leeds.ac.uk/educol/ncihe/ natrep.htm> (5 May 2004). For the response-Higher Education for the 21st Centuryto the Dearing Report refer to <http://www.lifelonglearning.co.uk/dearing/> (5 May 2004). 
2 Laura L. Hall, “Just-in-Time Learning: Web-Based/Internet Delivered Instruction,” Paper presented at Americas Conference on Information Systems AMCIS 99 (Milwaukee, WI: 13 - 15 August 1999), <http://aisel.isworld.org/password.asp?Vpath=AMCIS/1999\& PDFpath=319.pdf $>$ (25 Feb. 2004).

The enGauge 21st Century Skills (North Central Regional Educational Laboratory), <http://www.ncrel.org/engauge/skills/skill21.htm> (7 May 2004).

4 Julia Gaimster and David A. Gray, "From Transmitted Knowledge to Constructed Knowledge - e-Learning as Independent Inquiry," Paper presented at the European Conference on Educational Research (Lisbon: EERA, 11 - 14 September 2002).

$5 \quad$ Nikos Drakos and Ross Moore, Frodo vision and project goals (DFKI Knowledge Management Group, 1998), <http://www.dfki.uni-kl.de/frodo/ Proposal/index.html> (7 April 2003); Andrew Wileman, A Capital Idea (Cambridge, MA: MIT Press, 1999); Luiz Carlos de Sá Carvalho, Mônica Esteves Rodrigues, and Benito Diaz Paret, "Tacit and Formal Knowledge and Learning in Small Business: An Exploratory Study on the Perceptions of Successful Businessmen," in Proceedings of the 4th International Conference on Technology Policy and Innovation (Curitiba, Brazil, 2000), <http://in3. dem.ist.utl.pt/downloads/cur2000/papers/S17P06.PDF> (5 May 2004).

6 Eliat Aram and Dorothea Noble, "Educating prospective managers in the complexity of organizational life“. Management Learning 30, 3 (September 1999): 321-342; Geoff Walsham, Making a World of Difference: IT in a Global Context (New York, NY: Wiley, 2001).

7 Ashley D. Lloyd, Jenny Ure, R.J. Pooley, R.G. Dewar, and A. Cranmore, "Designing Enterprise Systems: Leveraging knowledge in a distributed pattern-building community," in Ricardo Gonçalves, Rajkumar Roy and A. Steiger-Garçao, eds., Advances in Concurrent Engineering, Proceedings of the $9^{\text {th }}$ ISPE International Conference on Concurrent Engineering (Cranfield, UK, 27-31 July 2002).

8 Márcia A. Pereira, "Designing Collaboration," Paper presented at the European Conference on Educational Research ECER2001, Symposium on Networked Learning in Higher Education (Lille, France, 5-8 September 2001); Márcia A. Pereira, "Pedagogical principles in web-based learning," in Proceedings of the Telematica 2001 Web-Based Education Conference (St. Petersburg, Russia, 18 - 21 June 2001).

Lev S. Vygotsky, Thought and Language (Cambridge, MA: MIT Press, 1962).

Márcia A. Pereira, ArchCAL: a conceptual basis for the application of information technology into learning and teaching technical subjects in architectural education, $\mathrm{PhD}$ Thesis (Sheffield: Department of Architectural Studies, University of Sheffield, 2000); Charles Crook, Computers and the Collaborative Experience of Learning (London: Routledge, 1996).

11 Donald A. Schön, The Reflective Practitioner: How Professionals Think in Action (Aldershot, UK: Arena, 1991); John Dewey, "How we think," in Jo Ann Boydston, ed., John Dewey: The later works, 1925-1953, Vol. 8 (Carbondale, IL: Southern Illinois University Press, 1986), pp. 105-352.

The Informal Knowledge obtained as a result of the learners' interaction with tools, via learning activities, can be linked to the course content, in an individual or collective basis. 
Dr. MARCIA PEREIRA is an e-learning specialist, who has been involved in computersupported learning and teaching since 1993. As a professional designer and educationalist specialised in the design of networked learning environments, she has been involved in different research and development projects in England, Scotland, and in Switzerland, such as: the "Virtual Learning Space" (Robert Gordon University, http://www.itlearningspacescot.ac.uk), "Build-IT and Creative Collaborations" (Swiss Federal Institute of Technology ETH Zürich, http://caad.arch.ethz.ch/buildit). Currently working as e-learning specialist at 'armadillo media' GmbH in Lucerne (Switzerland), she is actively involved on "myNetWorks" (online-learning environment for ecological engineers, http://www.myNetWorks.org) and providing didactical advice on the design of e-learning courses and learning activities. She is constantly publishing her work in international conferences and journals, seeking to discuss and share her ideas with the academic community. Her research interests are: socioconstructivism in e-learning, computer-supported collaborative learning/work, reflective practice, virtual learning environments, design of online courses and learning activities, elearning evaluation. Mailing address: Regensdorferstrasse 36, CH-8049 Zürich, Switzerland. E-mail: pereira@hispeed.ch.

Dr. EFFIE LAI-CHONG LAW is currently working as post-doc research fellow at Computer Engineering and Networks Laboratory (TIK) of Swiss Federal Institute of Technology (ETH Zürich), Switzerland. She has been actively engaging in research on Human Computer Interaction, especially usability engineering and technology-enhanced learning, as exemplified by her recent publications in the international reputed conferences, including NordiCHI 2002, INTERACT 2003, CHI 2004, CSCL 2003, ICNEE 2003, and ED-MEDIA 2004. With her training in educational and cognitive psychology, Dr. Law consistently demonstrates interest in these domains through publishing refereed journal papers, and co-authoring and co-editing book chapters on psychological research. Besides, she has published a series of technical reports on project evaluation and user trials in the context of a large-scale e-Learning European project UNIVERSAL (http://www.educanext.org/ubp). Her current research focuses on usability evaluation methods, computer supported collaborative learning/work (CSCL/W), e-Learning quality assurance management, learning theories and creativity. E-mail: law@tik.ee.ethz.ch. 